\title{
Mesothelin-Specific T Cell Cytotoxicity Against Triple Negative Breast Cancer Is Enhanced By 40s Ribosomal Protein Subunit 3-Treated Self- Differentiated Dendritic Cells
}

\section{Niphat Jirapongwattana ( $\nabla$ NIPHAT.JIR@GMAIL.COM )}

Mahidol University Faculty of Medicine Siriraj Hospital https://orcid.org/0000-0003-4720-4097

\section{Suyanee Thongchot}

Mahidol University Faculty of Medicine Siriraj Hospital

Wannasiri Chiraphapphaiboon

Mahidol University Faculty of Medicine Siriraj Hospital

Thaweesak Chieochansin

Mahidol University Faculty of Medicine Siriraj Hospital

Doonyapat Sa-nguanraksa

Mahidol University Faculty of Medicine Siriraj Hospital

Malee Warnnissorn

Mahidol University Faculty of Medicine Siriraj Hospital

Peti Thuwajit

Mahidol University Faculty of Medicine Siriraj Hospital

\section{Pa-Thai Yenchitsomanus}

Mahidol University Faculty of Medicine Siriraj Hospital

\section{Chanitra Thuwajit}

Mahidol University Faculty of Medicine Siriraj Hospital https://orcid.org/0000-0001-9506-6405

\section{Research Article}

Keywords: Dendritic cell, Self-differentiated myeloid-derived antigen-presenting-cell, Mesothelin, Triple negative breast cancer, $40 \mathrm{~S}$ ribosomal protein subunit 3

Posted Date: January 3rd, 2022

DOl: https://doi.org/10.21203/rs.3.rs-1165739/v1

License: (c) (i) This work is licensed under a Creative Commons Attribution 4.0 International License. Read Full License 


\section{Abstract}

Purpose Triple negative breast cancer (TNBC) is deficient in targeted treatment resulting in poor prognosis. Targeting overexpressed mesothelin (MSLN) using MSLN-specific T cells is an attractive treatment approach.

Methods The immunohistochemistry of MSLN in TNBC tissues were performed. A lentiviral vector harboring granulocyte-macrophage colony stimulating factor (GM-CSF), interleukin-4 (IL-4) and MSLN cDNAs was constructed to generate self-differentiated myeloid-derived antigen-presenting-cells reactive against tumor expressing MSLN dendritic cells (MSLN-SmartDC) for MSLN-specific T cell activation. The antigen specificity and cancer killing of activated $\mathrm{T}$ cells were accessed.

Results The high expression of MSLN was found in $32.8 \%$ all breast cancer subtypes and $57 \%$ in TNBC. High MSLN was significantly associated with the TNBC subtype and the absence of ER, PR and HER2. MSLN-SmartDC exhibited comparable phenotype to DC generated by exogenous cytokine treatment; addition of 40s ribosomal protein subunit 3 (RPS3), a toll-like receptor 4 ligand, enhanced DC maturation and function by upregulation of CD40, CD80 and CD83 expression and IL-12p70 secretion. MSLN-specific $\mathrm{CD}^{+}{ }^{+} \mathrm{CD} 69^{+} \mathrm{IFN}-\mathrm{\gamma}^{+} \mathrm{T}$ cells were detected in T cells activated by both MSLN-SmartDC and RPS3-MSLNSmartDC. MSLN-specific T cells activated by these DCs showed more specific killing capability against naturally expressed MSLN-HCC70 and artificially MSLN-overexpressing MDA-MB-231 compared to parental MDA-MB-231 in both 2 dimensional (2D)- and 3D-culture systems.

Conclusion High MSLN was observed in TNBC patients, a potential target for TNBC treatment. MSLNSmartDC could promote MSLN-specific T cell response against TNBC and RPS3 can enhance the cytolytic activity of these $T$ cells providing an alternative treatment approach for TNBC patients.

\section{Introduction}

Triple negative breast cancer (TNBC) is a subtype of breast cancer characterized by the absence of estrogen receptor (ER), progesterone receptor (PR), and human epidermal growth factor receptor 2 (HER2) [1]. TNBC is predominant in younger patients and demonstrates aggressive clinical features with poor prognosis [2]. Due to lacking of hormonal receptors and HER2, the current treatment for TNBC is limited to surgical resection and systemic chemotherapy [2], developing an alternative treatment approach for TNBC has been an active research area.

Dendritic cells (DCs)-based immunotherapy is aiming to induce an antigen-specific immune response through DCs presenting antigens to stimulate cancer-specific T cells given back to the patients to eliminate cancer cells $[3,4]$. Our group has previously demonstrated the ability of monocyte-derived DCs generated by lentiviral transduction of granulocyte-macrophage colony stimulating factor (GM-CSF), interleukin-4 (IL-4), and protein kinase cAMP-dependent type l-alpha regulatory subunit (PRKAR1A) encoded genes efficiently induced PRKAR1A-specific T cells killing against cholangiocarcinoma cells [5]. These DCs are called self-differentiated myeloid derived antigen-presenting cells reactive against tumor 
(SmartDCs) which can produce the cytokines required for DCs differentiation in autocrine manner and the tumor-associated antigen processing for cytotoxic T cells activation [5]. The SmartDC platform has been demonstrated an efficient antigen-specific T cells in leukemia, melanoma, and cholangiocarcinoma [5-9].

Mesothelin (MSLN) is a glycophosphatidylinositol-linked glycoprotein limitedly expressed in mesothelial cells but reported to be aberrantly expressed in various cancers such as ovarian cancer, pancreatic cancer, mesothelioma, and TNBC [10-13]. Importantly, it has been recognized as a potential target for cancer immunotherapy [12-14]. In breast cancer, several studies have reported the overexpression of MSLN specifically in TNBC and its high expression was associated with poor prognosis [11, 15-19]. The overexpression of MSLN in TNBC but limited expression in normal tissue highlighted the potential of MSLN as a target for T cell therapy.

The efficacy of T cells activated by DCs is greatly affected by the maturation status of DCs including the human leukocyte antigens (HLAs), co-stimulatory molecules and cytokines expressions [3]. In steady state, DCs express these molecules limitedly but upon encountered with factors derived from pathogen or cancer cells. DCs can be activated via the pattern recognition receptors signaling pathway such as tolllike receptors (TLRs) [20]. TLR ligands were used as adjuvant to induce immune response in several cancers [20-22]. Recently, TLR4 ligand called 40s ribosomal protein subunit 3 (RPS3) could induce DCs maturation [23]. Taken all together, this study is aimed to investigate the expression of MSLN in breast cancer tissues and the potential of genetically manipulated MSLN-SmartDC to induce MSLN-specific T cells responding against TNBC cells. Moreover, the effect of RPS3 treatment on MSLN-SmartDC immunophenotype and $T$ cells activity to enhance cytolytic activity of $T$ cells were reported. These findings suggest the impact of MSLN as a potential TNBC antigen, and MSLN-specific T cells produced from RPS3-MSLN-SmartDC present effective capability to destroy MSLN-positive TNBC cells.

\section{Materials And Methods}

\section{Immunohistochemistry}

The 351 cases of paraffin-embedded breast cancer tissues and clinicopathological data were collected under ethical approval (COA no. Si 580/2018). After antigen retrieving in pH 6 citrate buffer, the samples were stained with anti-human MSLN antibody (Santa Cruz Biotechnology, CA) at $4^{\circ} \mathrm{C}$ overnight. Then incubated with goat anti-mouse Envision (Dako, Carpinteria, CA) for 30 mins and HRP activity was detected by Dako-HRP detection kit (Dako) before counterstained with Mayer's hematoxylin. The samples were scanned at 400x by Scanscope slide scanner (Aperio Technologies, Vista, CA).

\section{Cell culture}

MDA-MB-231, HCC70 and T2 cell lines were from American Type Culture Collection (ATCC). Lenti- $\mathrm{X}^{\mathrm{TM}}$ HEK293T cell was from Takara Bio (Takara Bio, San Jose, CA). The Lenti-X ${ }^{T M}$ HEK293T cell, MDA-MB-231 and MSLN-MDA-MB-231, produced by lentiviral transduction, were maintained in DMEM with $10 \%$ fetal 
bovine serum (FBS) (Invitrogen, Carlsbad, CA). HCC70 was cultured in RPMI1640 with 10\% FBS (Invitrogen). The T2 cell line was cultured in RPMI1640 with 10\% FBS and 2 mM L-glutamine (Invitrogen).

\section{MSLN-SmartDC lentiviral vector construction and production}

The construction of lentiviral vector was performed as previously described [5]. Briefly, the full-length MSLN CDNA with restriction cut sites was amplified from HCC70 cells and cloned into pCDH1/GMCSF/IL-4 plasmid. The sequence integrity of MSLN-SmartDC plasmid was confirmed by Sanger's sequencing. A mock control pCDH1/GM-CSF/ IL-4 containing an irrelevant red fluorescence protein (IRFP), IRFP-SmartDC, was constructed [5]. MSLN-SmartDC lentiviral particle was produced by transfecting the MSLN-SmartDC plasmid along with lentiviral envelop plasmid, pMD2.G and lentiviral packaging plasmid, psPAX2 into Lenti- $X^{\mathrm{TM}}$ 293T. The lentiviral particle in the culture medium was collected and concentrated before measured for viral titer via qPCR Lentivirus Titration Kit (Applied Biological Materials, Inc., Richmond, Canada).

\section{Generation of MSLN-SmartDC and rhRPS3-treated MSLN-SmartDC}

The peripheral blood mononuclear cells (PBMCs) were isolated from $\mathrm{HLA}-\mathrm{A} 2^{+}$healthy donor blood by density centrifugation in Lymphocyte separating medium (Corning, Tewksbury, MA). The monocytes were isolated and incubated for $1 \mathrm{~h}$ at $37^{\circ} \mathrm{C}$. The non-adherence cells were collected and cryopreserved in human AB serum (Sigma Aldrich, St. Louis, MO) containing 10\% dimethyl sulfoxide until used. The monocytes were transduced with IRFP-SmartDC or MSLN-SmartDC at 75 multiplicity of infection (MOI) together with $10 \mu \mathrm{g} / \mathrm{ml}$ protamine sulfate in AIM-V medium (Invitrogen). On day 5 post-transduction, 1 $\mu \mathrm{g} / \mathrm{ml}$ of recombinant human RPS3 (Novus Biological, Littleton, $\mathrm{CO}$ ) was added. Monocytes cultured in $100 \mathrm{ng} / \mathrm{ml}$ of rhGM-CSF and $50 \mathrm{ng} / \mathrm{ml}$ of rhlL-4 (ImmunoTools, Friesoythe, Germany) for 5 days and treated with $100 \mathrm{ng} / \mathrm{ml}$ of rhIFN- $\gamma$ and rhTNF-a (ImmunoTools) for additional $48 \mathrm{~h}$ were served as positive control or conventional DC (conv. DC). All DCs were harvested on day 7 to check the activated characters.

\section{Activation and expansion of T cells by MSLN-SmartDC}

The cryopreserved T cells were thawed and co-cultured with DCs for $48 \mathrm{~h}$ at $10: 1$ ratio in AIM-V medium. T cells were expanded in AIM-V with $5 \%$ human AB serum (Sigma Aldrich), $20 \mathrm{ng} / \mathrm{ml}$ of rhlL-2, $10 \mathrm{ng} / \mathrm{ml}$ of rhlL-7 and $20 \mathrm{ng} / \mathrm{ml}$ of rhlL-15 (ImmunoTools) for 7 days.

\section{Flow cytometry analysis}

The immunophenotype of monocytes and DCs were accessed by anti-CD14, anti-CD40 and anti-HLA-DR (ImmunoTools); anti-CD80, anti-CD83 and anti-CD86 antibodies (Thermo Fisher Scientific, Rockford, IL). Isotype antibodies were used as negative controls.

The memory T cell subsets were stained by anti-CD3, anti-CD45RA and anti-CD62L (ImmunoTools); antiCD4 and anti-CD8 (Thermo Fisher Scientific). For intracellular cytokines, the activated T cells were restimulated with $10 \mu \mathrm{g}$ of MSLN antigenic peptides (SLLFLLFSL and VLPLTVAEV) (GenScript, Jiangsu, 
China) $[10,24]$ for $6 \mathrm{~h}$ in the presence of BD GolgiPlug (BD Biosciences, San Jose, CA). The cells were stained with anti-CD3, anti-CD4, anti-CD8 and anti-CD69 (Thermo Fisher Scientific). Cells were fixed in BD Cytofix/Cytoperm (BD Biosciences), stained with anti-IFN-y antibody (Thermo Fisher Scientific).

The flow cytometry data of DCs and T cell immunophenotypes were acquired by CytoFLEX (Beckman Coulter, Atlanta, GO); the intracellular cytokine staining was acquired by BD LSRFortessa ${ }^{T M}$ (BD Biosciences). The data were analyzed by FlowJo VX software (Treestar, USA) and shown as mean fluorescence intensity (MFI) of each marker normalized by isotype control.

\section{Enzyme-linked immunosorbent assay (ELISA)}

GM-CSF, IL-4 and IL-12p70 were measured using Human GM-CSF, IL-4 and IL-12p70 Quantikine ELISA kits (R\&D systems, Inc., Minneapolis, MN). IFN- $\gamma$ was measured in medium collected from activated T cells cocultured with target cancer cells using Human IFN-y Quantikine ELISA kit (R\&D systems, Inc.).

\section{Enzyme-linked immunosorbent spot assay (ELISpot)}

The IFN-y ELISpot assay was performed using Human IFN-y ELISpot ${ }^{\mathrm{BASIC}}$ kit (Mabtech, Inc., Cincinnati, $\mathrm{OH})$. Briefly, $15 \mu \mathrm{g} / \mathrm{ml}$ of IFN-y capture antibody was coated for overnight at $4^{\circ} \mathrm{C}$. The $2 \times 10^{5}$ activated T cells were then re-stimulated with $1 \times 10^{4} \mathrm{MSLN}$ peptides-pulsed HLA-A2 ${ }^{+} \mathrm{T} 2$ cells. T cells treated with 20 $\mathrm{ng} / \mathrm{ml}$ of phorbol 12-myristate 13-acetate and $1 \mu \mathrm{g} / \mathrm{ml}$ of ionomycin (Sigma Aldrich) were served as positive controls. After removing these T cells, $1 \mu \mathrm{g} / \mathrm{ml}$ of bionylated-IFN- $\gamma$ antibody was incubated for 2 $\mathrm{h}$ and ALP-conjugated streptavidin for $1 \mathrm{~h}$. The IFN- $\gamma$ spots were evaluated by 5-bromo-4-chloro-3-indolyl phosphate/nitro blue tetrazolium plus substrate (Mabtech, Inc.) and analyzed by ELISpot plate reader (BIOREADER ${ }^{\circledR} 5000$ Fy, BIOSyS, Dhaka, Bangladesh).

\section{Western blot analysis}

Cancer cell lysates were prepared in RIPA Lysis Buffer System (Santa Cruz Biotechnology), separated in SDS-PAGE and transferred to PVDF membrane (GE Healthcare, Buckinghamshire, UK). The membrane was incubated with anti-MSLN and anti- $\beta$-actin antibodies (Santa Cruz Biotechnology). The HRPconjugated goat anti-mouse antibody (Cell Signaling Technologies, Danvers, MA) was added and the signal was detected by Clarity ${ }^{\mathrm{TM}}$ western ECL substrate (Bio-Rad laboratories, Philadelphia, PA) under Gel Doc instrument (G:Box Chemi XR5, Cambridge, UK). The band intensity was analyzed by Image J software $(\mathrm{NIH}$, Bethesda, MD).

\section{Two-dimensional (2D) cancer killing by luciferase assay}

T cells were co-cultured with luciferase expressing HCC70, MDA-MB-231 and MSLN-MDA-MB-231 cells at Effector: Target ratio at $1: 1,5: 1$ and $10: 1$ for $24 \mathrm{~h}$. The luciferase activity was determined using Pierce $^{\text {TM }}$ Firefly Luciferase Glow Assay Kit (Thermo Fisher) and Lumat LB 9507 Ultra-sensitive 
Luminometer (Berthold Technologies GmbH \& Co. KG., Bad Wildbad, Germany). The percentage of cancer cell lysis was calculated:

$\%$ Cancer cell lysis $=100-\left(\frac{\text { lucCancer } \text { cocultured activated } T \text { cells }_{\text {lucCancercocultured unactivated } T \text { cells }}}{\text { lut }} \times 100\right)$

\section{D-spheroid cancer killing assay}

The $1 \times 10^{3}$ target mWasabi-transduced cancer cells were formed into spheroid in 96-well ultra-low attachment plates (Corning) in $200 \mu \mathrm{l}$ culture medium containing $2.5 \%$ cold Matrigel $^{\mathrm{TM}}$ (BD Biosciences) by centrifugation at $300 \mathrm{~g}$ for 3 mins at $4^{\circ} \mathrm{C}$. The spheroid was incubated for 4 days with CellTracker ${ }^{\mathrm{TM}}$ Orange CMRA Dye (Invitrogen)-labelled activated T cells at Effector: Target ratios at 1: 1, 5:1, $10: 1$ and $20: 1$ for $48 \mathrm{~h}$. The mWasabi and CMRA fluorescence signals were detected by inverted fluorescence microscope and CellSense Standard program version 1.15 (Olympus, Middlesex, UK).

\section{Statistical analysis}

The correlation between MSLN score and clinicopathological data were accessed by Fisher's exact test. The prognostic value of MSLN with patients' survival time was determined by Kaplan-Meier method and Log-rank test. The difference between two conditions were accessed by Student's $t$ test and one-way ANOVA and Tukey's post-hoc test for more than two conditions. The statistical analysis was performed in SPSS 17.0 (IBM, Armonk, NY), whereas GraphPad prism V (GraphPad Software, La Jolla, CA) was used for one-way ANOVA. All results were shown as mean $\pm S D$ from at least three independent experiments. $A$ $p$-value $<0.05$ was considered as statistically significant.

\section{Results}

\section{MSLN expression in breast cancer tissues}

All patient cases were female with mean age of $54 \pm 11.5$ years diagnosed as luminal, HER2-positive and TNBC subtypes for $15 \%, 38 \%$ and $47 \%$ (Table 1). The cytoplasmic and membranous patterns of MSLN positive were detected in cancer cells with various levels (Fig. 1a-c). No MSLN expression was observed in the adjacent normal mammary cells (Fig. 1d), as well as stromal cells (Fig. 1e) and immune cells (Fig. 1f). Among 351 total cases, 115 cases (32.8\%) were positive for MSLN, $57 \%$ for TNBC subtype, $14.9 \%$ in HER2-positive and $1.9 \%$ in luminal subtypes (Fig. 1g). The mean MSLN expression score was significantly higher in TNBC subtype than that in HER2-positive and luminal subtype (Fig. 1h). MSLN was significantly correlated with the absence of ER, PR and HER2, and TNBC subtype (Table 1). There was no association between MSLN and overall or disease-free survival in all samples, HER2-positive and TNBC subtypes (Supplementary Fig. 1).

\section{Generation and immunophenotyping of MSLN-SmartDC and RPS3-MSLN-SmartDC}


MSLN-SmartDC was generated by transducing the lentiviral vector containing GM-CSF, IL-4 and MSLN (Fig. 2a) into PBMCs-derived monocytes from four HLA-A2 positive healthy donors. All DCs demonstrated dendritic-like morphology (Fig. 2b). GM-CSF and IL-4 were significantly detected higher levels in both MSLN-SmartDC and RPS3-treated MSLN-SmartDC compared to monocytes (Fig. $2 \mathrm{c}$ and 2d). The significant reduction of CD14 monocyte marker in all DCs conditions (Fig. 2e) and mature DC markers including CD40, HLA-DR, CD83 and CD86 (Fig. 2f-j) were significantly increased compared to monocytes. The addition of RPS3 to MSLN-SmartDC could significantly increase CD40, CD80 and CD83 (Fig. $2 f$ and $2 \mathrm{~h}-\mathrm{i})$ compared to those of MSLN-SmartDC. Moreover, IL-12p70 was significantly increased in MSLNSmartDC with RPS3 (Fig. 2k).

\section{Immunophenotype of T cells activated by MSLN-SmartDC and RPS3-MSLN-SmartDC}

The results showed slight changes in $\mathrm{CD} 4^{+}$and $\mathrm{CD} 8^{+} \mathrm{T}$ cells frequencies and memory $\mathrm{T}$ cells subsets compared to those in PBMCs at day 0 (Supplementary Fig. 2a-b). Re-stimulation with MSLN antigenic peptides in T cells activated by MSLN-SmartDC and RPS3-MSLN-SmartDC showed significantly higher number of IFN- $\gamma$ than those without peptide treatment (Fig. 3a). The frequency of IFN- $\gamma^{+} \mathrm{CD} 8^{+} \mathrm{T}$ cells after MSLN peptides challenging were found at higher levels in MSLN-SmartDC- and RPS3-MSLN-activated T cells than unactivated DC- and IRFP-activated T cells (Fig. 3b). Only RPS3-MSLN-activated T cells revealed significant increased IFN- $\gamma^{+} \mathrm{CD} 8^{+} \mathrm{T}$ cells (Fig. 3b). The dual expressions of CD69 and IFN- $\gamma$ were observed in MSLN- and RPS3-MSLN-activated T cells, but very low level in T cells treated with unactivated- and IRFP-activated T cells (Fig. 3c). The frequency of MSLN-specific CD69+ IFN-g ${ }^{+}$CD $8{ }^{+}$T cells activated by RPS3-MSLN-SmartDC was clearly higher than unactivated and IRFP-activated T cells. Moreover, $\mathrm{CD} 69^{+} \mathrm{IFN}-\mathrm{\gamma}^{+} \mathrm{CD} 8^{+} \mathrm{T}$ cells in RPS3-MSLN-activated T cells was significantly higher compared to those without peptides re-stimulation.

\section{D cytolytic activity of MSLN-SmartDC- and RPS3-MSLN-SmartDC-activated T cells}

The MSLN showed the highest level in MSLN-MDA-MB-231, followed by HCC70, whereas MDA-MB-231 had no MSLN (Fig. 4a). The IFN-y releasing from RPS3-MSLN-activated T cells after co-culturing with MSLN-MDA-MB-231 and HCC70 cells was higher than MSLN-activated T cells and significantly higher than those of IRFP-activated T cells (Fig. 4b). No changes of IFN- $\gamma$ secreted from T cells cocultured with MDA-MB-231.

The results exhibited no difference in MDA-MB-231 cell lysis co-cultured with both MSLN-activated T cells and RPS3-MSLN-activated T cells at Effector: Target ratios of $1: 1,5: 1$ and $10: 1$ (Fig. 4c). T cells activated by MSLN-SmartDC demonstrated significantly higher MSLN-MDA-MB-231 cell cytotoxicity compared to IRFP-activated T cells at $10: 1$ ratio (Fig. 4d). At $10: 1$, T cells activated by RPS3-MSLNSmartDC could significantly induce MSLN-MDA-MB-231 cell lysis more than MSLN-activated T cells (Fig. 4d). In HCC70, T cells activated by MSLN-SmartDC and RPS3-MSLN-SmartDC demonstrated higher killing activity than IRFP-activated T cells (Fig. 4e). However, only RPS3-MSLN-activated T cells achieved 
statistical significance of cancer cell killing compared to that of IRFP-activated T cells at ratios of $5: 1$ and $10: 1$ (Fig. 4e).

\section{D cytolytic activity of T cells activated by MSLN-SmartDC and RPS3-MSLN-SmartDC}

MDA-MB-231 spheroid co-cultured with activated T cells or unactivated T cells for $48 \mathrm{~h}$ revealed no differences in mWasabi green fluorescence signals representing viable cancer cells (Fig. 5a). MSLN-MDAMB-231 spheroid co-cultured with T cells activated by MSLN-SmartDC significantly exhibited lower viable cells compared to those of unactivated T cells at $20: 1$ (Fig. 5b). T cells activated by RPS3-MSLNSmartDC had significant decrease viable cells compared to unactivated T cells $(p<0.001)$, IRFP-activated and MSLN-activated T cells at $20: 1$ (Fig. 5b). RPS3 could enhance DCs activation that subsequently increase T cells capability to recognize MSLN-MDA-MB-231 cells. For HCC70 spheroid, the significant decreased fluorescence signal was observed in MSLN-SmartDC-activated T cells at ratio $20: 1$ compared to unactivated T cells. Moreover, T cells activated by RPS3-MSLN-SmartDC demonstrated significant reduction of mWasabi fluorescence signal compared to both unactivated and IRFP-activated T cells at 10 $: 1$ and $20: 1$ (Fig. 5c).

\section{Discussion}

The insensitivity to endocrine- and HER2-targeted therapies in TNBC limits the available treatment to systemic chemotherapy and surgical resection with unfavorable outcome [2]. Targeting the protein overexpressed in TNBC such as MSLN is currently an active area of immunotherapy [11,25]. High expression of MSLN in TNBC reported in this study was consistent with the previous studies with the range of MSLN around 37-67\% [11, 15-19]. The DCs-based immunotherapy is another potential approach for the TNBC treatment that could promote the antigen-specific immune response which leading to clinical response as observed in various cancers including melanoma, leukemia, cholangiocarcinoma and pancreatic cancer $[3,5-7,10,21]$. In this study, self-differentiated DCs presenting MSLN antigen, called MSLN-SmartDC was developed and shown to promote the MSLNspecific immune response against TNBC. The effect of RPS3, a TLR4 ligand, on MSLN-SmartDC immunophenotype and T cells activation capability was significantly enhanced. Since high MSLN expression was confirmed in most TNBC cases, the MSLN-specific T cell production by MSLN-SmartDC platform is highlighted for an alternative T cell treatment in TNBC patients.

Several studies have reported the utility of DCs generated by lentiviral transduction of cytokine genes for DCs differentiation and by tumor-associated antigen gene to induce antigen-specific immune response leading to the tumor growth inhibition [5-9]. Our MSLN-SmartDC demonstrated the consistent immunophenotypes with DCs generated by recombinant GM-CSF and IL-4 observed by the significant down-regulation of CD14 monocyte marker, while the markers of DCs such as CD40, CD83, CD86 and HLA-DR were significantly upregulated. Moreover, the increased MSLN-SmartDC maturation profile by upregulation of the costimulatory molecules; CD40, CD80, CD83 and IL-12p70 production were observed. CD40, CD80 and CD83 increment in RPS3- MSLN-SmartDC compared to MSLN-SmartDC supported the 
previous findings that RPS3 could activate DC maturation [23]. These characters suggest the potential of higher T cell activation of RPS3-MSLN-SmartDC than MSLN-SmartDC. The upregulation of CD40 in matured DCs was required for the DCs licensing by CD40L-expressing T cells which further augment the costimulatory molecules and cytokine production initiated by RPS3 treatment [26-28]. This is the limitation of the study, but it may be explained that RPS3 induces MSLN-SmartDC maturation and the upregulation of CD40 can further augment the maturation initiated by TLR4 signaling pathway [28].

The T cells characteristics after co-cultured with MSLN-SmartDC with or without RPS3 showed slightly changed in frequencies of $\mathrm{CD} 4^{+}, \mathrm{CD} 8^{+}$and the memory $\mathrm{T}$ cells subsets. This may be due to the effect of cytokines used during $T$ cells expansion process which can non-specifically promote $T$ cell proliferation $[29,30]$. However, the presence of MSLN-specific $C D 8^{+} T$ cells recognized HLA-A2 restricted MSLN antigenic peptides $[10,24]$ in activated by MSLN-SmartDC and RPS3-MSLN-SmartDC compared to the negative control conditions were observed. Although there was a trend toward increased MSLN-specific T cells in RPS3-MSLN-SmartDC compared to other conditions, it did not achieve the statistically significant levels. The addition of RPS3 to MSLN-SmartDC could not affect the frequency of MSLN-specific T cells. It is possible that the upregulated factors found in RPS3-MSLN-SmartDC including CD40, CD80 and IL12 p70 exert their effect on the quality of antigen-specific $T$ cells in particular the cytotoxicity function rather than the quantity or the frequency of $T$ cells $[26,31,32]$. This may be supported by the findings of significant increase of IFN- $\gamma^{+}$and $C D 69^{+}$IFN- $\gamma^{+}$T cells driven by RPS3- MSLN-SmartDC. T cells activated by MSLN-SmartDC or RPS3-MSLN-SmartDC promoted TNBC cell killing in effector cells and antigendependent manners. These findings are in agreement with previous studies in SmartDC system in different antigens and cancer models [5-8]. Moreover, T cells activated by RPS3-MSLN-SmartDC demonstrated enhanced cytolytic activity against MSLN expressing cancer cells. This was associated with the increased IFN-y production and may explain effective target cells lysis by RPS3-MSLN-activated T cells.

The cytolytic activity of T cells activated by MSLN-SmartDC in 3D-cancer spheroid was consistent with that observed in 2D culture system. To minimize the effect of non-specific T cells killing mediated by HLA-mismatched between the target cells and T cells, the healthy donors with HLA-A2 partially matched with MDA-MB-231, but not HCC70 (HLA-A3), were selected. Using MSLN-MDA-MB-231 in comparison with parental MDA-MB-231 could eliminate the intrinsic factors of target cells that may interfere with the $T$ cells cytolytic activity, except the presence of MSLN. Future study using the ex vivo generated SmartDC and T cells to kill patient-derived TNBC cells can eliminate this limitation. The addition of RPS3 in MSLNSmartDC trend toward increased cancer cell cytotoxicity in HCC70. Collectively, the obtained findings herein highlight the efficacy of T cells activated by MSLN-SmartDC to eliminate MSLN-expressing TNBC cells; and the addition of RPS3 to MSLN-SmartDC prior co-cultured with T cells enhances T cells cytolytic activity against the TNBC cells.

The MSLN-specific T cells in cancer patients have been reported [24, 33, 34]. Different approaches of MSLN targeted treatment demonstrated a safety and efficacy in several cancers [13, 25, 35]. Targeting MSLN in TNBC using T cells activated by MSLN-SmartDC and RPS3-MSLN-SmartDC may provide a 
potential safe and effective treatment for TNBC patients. The current trend in breast cancer treatment approach has now shifted from the monotherapy to the combinational treatment involving several interventions such as surgery, radiation, chemotherapy and immunotherapy [2]. Combination of treatments targeting the bulk tumor mass or the stromal cells and reduce the immunosuppressive signal in tumor microenvironment via surgery, chemotherapy and checkpoint inhibitor together with the DCsbased immunotherapy that promote the antigen-specific $T$ cells could result in significant improved clinical outcome [36-39]. Therefore, further investigation of MSLN-SmartDC and RPS3-MSLN-SmartDC in combination with other treatment approaches is a great promise for the novel treatment modality in TNBC patients.

In conclusion, the efficacy of MSLN-SmartDC promotes MSLN-specific immune response killing MSLNexpressing TNBC cells is successfully developed. The MSLN-SmartDC maturation enhancement by RPS3 treatment can improve the cytolytic activity of T cells against high MSLN TNBC cells. These findings demonstrate the potential of MSLN-SmartDC and RPS3-MSLN-SmartDC to activate MSLN-specific T cells as an alternative treatment for TNBC patients.

\section{Declarations}

\section{Acknowledgements}

The authors gratefully acknowledge Midcareer Research Grant, National Research Council of Thailand (Grant number RSA6280091) supported CT, Siriraj Graduate Scholarship given to NJ, and TRF-IRN Scholarship (scholarship number IRN5801PHDW05) to WC. Special thanks to Miss Surat Phumphuang for her effort in clinicopathological data collection. The authors would like to thank Emeritus Professor James A. Will for English edition of the manuscript.

\section{Author contribution}

CT and PY conceived the study. NJ, TC, PT, PY and CT designed the experiments. NJ, ST and WC performed the experiments. DS and MW performed data resource and analysis. NJ, ST and CT analyzed and interpreted the data. CT supervised the overall research. NJ, ST and CT wrote the paper. CT reviewed and/or edited the paper.

\section{Fundings}

This work has been funded by Midcareer Research Grant (scholarship number RSA6280091), National Research Council of Thailand to CT and Graduate Grant, National Research Council of Thailand to NJ and Graduate Grants, National Research Council of Thailand to NJ and TRF-IRN Scholarship (scholarship number IRN5801PHDW05) to WC.

\section{Conflict of interest}

The authors declare that they have no conflict of interest. 


\section{Ethics approval and consent to participate}

All experiments followed a protocol approved by Siriraj Institutional Review Board (COA no. Si580/2018) and with the 1964 Helsinki declaration and its later amendments or comparable ethical standards.

\section{Patient consent for publication}

All blood donors in this study provided written informed consent for the use of blood samples for research.

\section{References}

1. Foulkes WD, Smith IE, Reis-Filho JS (2010) Triple-negative breast cancer. N Eng J Med 363:19381948. doi: 10.1056/NEJMra1001389

2. Waks AG, Winer EP (2019) Breast cancer treatment: a review. JAMA 321:288-300. doi: 10.1001/jama.2018.19323

3. Saxena M, Bhardwaj N (2018) Re-emergence of dendritic cell vaccines for cancer treatment. Trends Cancer 4:119-137. doi: 10.1016/j.trecan.2017.12.007

4. Bernhard H, Neudorfer J, Gebhard K, Conrad H, Hermann C, Nährig J, Fend F, Weber W, Busch DH, Peschel C (2008) Adoptive transfer of autologous, HER2-specific, cytotoxic T lymphocytes for the treatment of HER2-overexpressing breast cancer. Cancer Immunol Immunother 57:271-280. doi: $10.1007 / \mathrm{s} 00262-007-0355-7$

5. Panya A, Thepmalee C, Sawasdee N, Sujjitjoon J, Phanthaphol N, Junking M, Wongkham S, Yenchitsomanus PT (2018) Cytotoxic activity of effector T cells against cholangiocarcinoma is enhanced by self-differentiated monocyte-derived dendritic cells. Cancer Immunol Immunother 67:1579-1588. doi: 10.1007/s00262-018-2212-2

6. Sundarasetty BS, Chan L, Darling D, Giunti G, Farzaneh F, Schenck F, Naundorf S, Kuehlcke K, Ruggiero E, Schmidt M, von Kalle C, Rothe M, Hoon DSB, Gerasch L, Figueiredo C, KoehI U, Blasczyk R, Gutzmer R, Stripecke R (2015) Lentivirus-induced 'Smart' dendritic cells: pharmacodynamics and GMP-compliant production for immunotherapy against TRP2-positive melanoma. Gene Ther 22:707-720. doi: $10.1038 /$ gt.2015.43

7. Sundarasetty BS, Singh VK, Salguero G, Geffers R, Rickmann M, Macke L, Borchers S, Figueiredo C, Schambach A, Gullberg U, Provasi E, Bonini C, Ganser A, Woelfel T, Stripecke R (2013) Lentivirusinduced dendritic cells for immunization against high-risk WT1(+) acute myeloid leukemia. Human gene therapy 24:220-237. doi: 10.1089/hum.2012.128

8. Bialek-Waldmann JK, Domning S, Esser R, Glienke W, Mertens M, Aleksandrova K, Arseniev L, Kumar S, Schneider A, Koenig J, Theobald SJ, Tsay HC, Cornelius ADA, Bonifacius A, Eiz-Vesper B, Figueiredo C, Schaudien D, Talbot SR, Bleich A, Spineli LM, von Kaisenberg C, Clark C, Blasczyk R, Heuser M, Ganser A, Köhl U, Farzaneh F, Stripecke R (2021) Induced dendritic cells co-expressing GM- 
CSF/IFN- $\mathrm{a} / \mathrm{tWT} 1$ priming T and B cells and automated manufacturing to boost GvL. Molecular therapy Methods \& clinical development 21:621-641. doi: 10.1016/j.omtm.2021.04.004

9. Pincha M, Sundarasetty BS, Salguero G, Gutzmer R, Garritsen H, Macke L, Schneider A, Lenz D, Figueiredo C, Blasczyk R, Ruggiero E, Schmidt M, von Kalle C, Puff C, Modlich U, von der Leyen H, Wicke DC, Ganser A, Stripecke R (2012) Identity, potency, in vivo viability, and scaling up production of lentiviral vector-induced dendritic cells for melanoma immunotherapy. Hum Gene Ther Methods 23:38-55. doi: 10.1089/hgtb.2011.170

10. de Goeje PL, Klaver Y, Kaijen-Lambers MEH, Langerak AW, Vroman H, Kunert A, Lamers CHJ, Aerts JGJV, Debets R, Hendriks RW (2018) Autologous dendritic cell therapy in mesothelioma patients enhances frequencies of peripheral CD4 T cells expressing HLA-DR, PD-1, or ICOS. Front Immunol. 9. doi: 10.3389/fimmu.2018.02034

11. Tchou J, Wang L-C, Selven B, Zhang H, Conejo-Garcia J, Borghaei H, Kalos M, Vondeheide RH, Albelda SM, June CH, Zhang PJ (2012) Mesothelin, a novel immunotherapy target for triple negative breast cancer. Breast Cancer Res Treat 133:799-804. doi: 10.1007/s10549-012-2018-4

12. Le K, Wang J, Zhang T, Guo Y, Chang H, Wang S, Zhu B (2020) Overexpression of mesothelin in pancreatic ductal adenocarcinoma (PDAC). Int J Med Sci 17:422-427. doi: 10.7150/ijms.39012

13. Haas AR, Tanyi JL, O'Hara MH, Gladney WL, Lacey SF, Torigian DA, Soulen MC, Tian L, McGarvey M, Nelson AM, Farabaugh CS, Moon E, Levine BL, Melenhorst JJ, Plesa G, June CH, Albelda SM, Beatty GL (2019) Phase I study of lentiviral-transduced chimeric antigen receptor-modified T cells recognizing mesothelin in advanced solid cancers. Mol Ther 27:1919-1929. doi:

10.1016/j.ymthe.2019.07.015

14. Hassan R, Ho M (2008) Mesothelin targeted cancer immunotherapy. Eur J Cancer 44:46-53. doi: 10.1016/j.ejca.2007.08.028

15. Parinyanitikul N, Blumenschein GR, Wu Y, Lei X, Chavez-Macgregor M, Smart M, Gonzalez-Angulo AM (2013) Mesothelin expression and survival outcomes in triple receptor negative breast cancer. Clin Breast Cancer 13:378-384. doi: 10.1016/j.clbc.2013.05.001

16. Tozbikian G, Brogi E, Kadota K, Catalano J, Akram M, Patil S, Ho AY, Reis-Filho JS, Weigelt B, Norton L, Adusumilli PS, Wen HY (2014) Mesothelin expression in triple negative breast carcinomas correlates significantly with basal-like phenotype, distant metastases and decreased survival. PLoS One 9:e114900-e114900. doi: 10.1371/journal.pone.0114900

17. Bayoglu IV, Kucukzeybek BB, Kucukzeybek Y, Varol U, Yildiz I, Alacacioglu A, Akyol M, Demir L, Dirican A, Yildiz Y, Salman T, Tarhan MO (2015) Prognostic value of mesothelin expression in patients with triple negative and HER2-positive breast cancers. Biomed Pharmacother 70:190-195. doi:

10.1016/j.biopha.2015.01.019

18. Li YR, Xian RR, Ziober A, Conejo-Garcia J, Perales-Puchalt A, June CH, Zhang PJ, Tchou J (2014) Mesothelin expression is associated with poor outcomes in breast cancer. Breast Cancer Res Treat 147:675-684. doi: 10.1007/s10549-014-3077-5 
19. Suzuki T, Yamagishi Y, Einama T, Koiwai T, Yamasaki T, Fukumura-koga M, Ishibashi Y, Takihata $Y$, Shiraishi T, Miyata Y, Iwasaki T, Shinto E, Sato K, Ueno H, Yamamoto J, Kishi Y, Tsuda H (2020) Membrane mesothelin expression positivity is associated with poor clinical outcome of luminal-type breast cancer. Oncol Lett 20:193. doi: 10.3892/ol.2020.12055

20. Vermaelen K (2019) Vaccine strategies to improve anti-cancer cellular immune responses. Front Immunol 10:8. doi: 10.3389/fimmu.2019.00008

21. Mehrotra S, Britten CD, Chin S, Garrett-Mayer E, Cloud CA, Li M, Scurti G, Salem ML, Nelson MH, Thomas MB, Paulos CM, Salazar AM, Nishimura MI, Rubinstein MP, Li Z, Cole DJ (2017) Vaccination with poly (IC:LC) and peptide-pulsed autologous dendritic cells in patients with pancreatic cancer. $\mathrm{J}$ Hematol Oncol 10:82. doi: 10.1186/s13045-017-0459-2

22. Chow LQM, Morishima C, Eaton KD, Baik CS, Goulart BH, Anderson LN, Manjarrez KL, Dietsch GN, Bryan JK, Hershberg RM, Disis ML, Martins RG (2017) Phase lb trial of the Toll-like receptor 8 agonist, motolimod (VTX-2337), combined with cetuximab in patients with recurrent or metastatic SCCHN. Clin Cancer Res 23:2442-2450. doi: 10.1158/1078-0432.Ccr-16-1934

23. Park HJ, Jang G-Y, Kim YS, Park JH, Lee SE, Vo M-C, Lee J-J, Han HD, Jung ID, Kang TH, Park Y-M (2019) A novel TLR4 binding protein, 40S ribosomal protein S3, has potential utility as an adjuvant in a dendritic cell-based vaccine. J Immunother Cancer 7:60. doi: 10.1186/s40425-019-0539-7

24. Thomas AM, Santarsiero LM, Lutz ER, Armstrong TD, Chen Y-C, Huang L-Q, Laheru DA, Goggins M, Hruban RH, Jaffee EM (2004) Mesothelin-specific CD8(+) T cell responses provide evidence of in vivo cross-priming by antigen-presenting cells in vaccinated pancreatic cancer patients. J Exp Med 200:297-306. doi: 10.1084/jem.20031435

25. Del Bano J, Florès-Florès R, Josselin E, Goubard A, Ganier L, Castellano R, Chames P, Baty D, Kerfelec B (2019) A Bispecific antibody-based approach for targeting mesothelin in triple negative breast cancer. Front Immunol 10:1593-1593. doi: 10.3389/fimmu.2019.01593

26. Ara A, Ahmed KA, Xiang J (2018) Multiple effects of CD40-CD40L axis in immunity against infection and cancer. Immunotargets Ther 7:55-61. doi: 10.2147/ITT.S163614

27. Tay NQ, Lee DCP, Chua YL, Prabhu N, Gascoigne NRJ, Kemeny DM (2017) CD40L expression allows $\mathrm{CD} 8+\mathrm{T}$ cells to promote their own expansion and differentiation through dendritic cells. Front Immunol 8. doi: 10.3389/fimmu.2017.01484

28. Michael Dohnal A, Luger R, Paul P, Fuchs D, Felzmann T (2009) CD40 ligation restores type 1 polarizing capacity in TLR4-activated dendritic cells that have ceased interleukin-12 expression. $\mathrm{J}$ Cell Mol Med 13:1741-1750. doi: 10.1111/j.1582-4934.2008.00584.x

29. Ross SH, Cantrell DA (2018) Signaling and function of interleukin-2 in T lymphocytes. Annu Rev Immunol 36:411-433. doi: 10.1146/annurev-immunol-042617-053352

30. Drake A, Kaur M, Iliopoulou BP, Phennicie R, Hanson A, Chen J (2016) Interleukins 7 and 15 maintain human T cell proliferative capacity through STAT5 signaling. PLoS One 11:e0166280. doi: 10.1371 /journal.pone. 0166280 
31. Agarwal P, Raghavan A, Nandiwada SL, Curtsinger JM, Bohjanen PR, Mueller DL, Mescher MF (2009) Gene regulation and chromatin remodeling by IL-12 and type I IFN in programming for CD8 T cell effector function and memory. J Immunol 183:1695. doi: 10.4049/jimmunol.0900592

32. Chen L, Flies DB (2013) Molecular mechanisms of T cell co-stimulation and co-inhibition. Nat Rev Immunol 13:227-242. doi: 10.1038/nri3405

33. Chen Y, Ayaru L, Mathew S, Morris E, Pereira SP, Behboudi S (2014) Expansion of anti-mesothelin specific CD4+ and CD8+ T cell responses in patients with pancreatic carcinoma. PLoS One 9:e88133. doi: $10.1371 /$ journal.pone. 0088133

34. Zhenjiang L, Rao M, Luo X, Sandberg E, Bartek J, Schoutrop E, von Landenberg A, Meng Q, Valentini D, Poiret T, Sinclair G, Peredo I-H, Dodoo E, Maeurer M (2017) Mesothelin-specific immune responses predict survival of patients with brain metastasis. EBioMedicine 23:20-24. doi: https://doi.org/10.1016/j.ebiom.2017.08.024

35. Zhang J, Khanna S, Jiang Q, Alewine C, Miettinen M, Pastan I, Hassan R (2017) Efficacy of antimesothelin immunotoxin RG7787 plus Nab-paclitaxel against mesothelioma patient-derived xenografts and mesothelin as a biomarker of tumor response. Clin Cancer Res 23:1564-1574. doi: 10.1158/1078-0432.CCR-16-1667

36. Waldman AD, Fritz JM, Lenardo MJ (2020) A guide to cancer immunotherapy: from T cell basic science to clinical practice. Nat Rev Immunol 20:651-668. doi: 10.1038/s41577-020-0306-5

37. Bulgarelli J, Tazzari M, Granato AM, Ridolfi L, Maiocchi S, de Rosa F, Petrini M, Pancisi E, Gentili G, Vergani B, Piccinini F, Carbonaro A, Leone BE, Foschi G, Ancarani V, Framarini M, Guidoboni M (2019) Dendritic cell vaccination in metastatic melanoma turns "non-T cell inflamed" into "T-cell inflamed" tumors. Front Immunol. 10. doi: 10.3389/fimmu.2019.02353

38. Sawasdee N, Thepmalee C, Sujjitjoon J, Yongpitakwattana P, Junking M, Poungvarin N, Yenchitsomanus PT, Panya A (2020) Gemcitabine enhances cytotoxic activity of effector Tlymphocytes against chemo-resistant cholangiocarcinoma cells. Int immunopharmacol 78:106006. doi: 10.1016/j.intimp.2019.106006

39. Kodumudi KN, Ramamoorthi G, Snyder C, Basu A, Jia Y, Awshah S, Beyer AP, Wiener D, Lam L, Zhang H, Greene MI, Costa RLB, Czerniecki BJ (2019) Sequential anti-PD1 therapy following dendritic cell vaccination improves survival in a HER2 mammary carcinoma model and identifies a critical role for CD4 T cells in mediating the response. Front Immunol. 10. doi: 10.3389/fimmu.2019.01939

\section{Tables}

Table 1 is not available with this version.

\section{Figures}


a

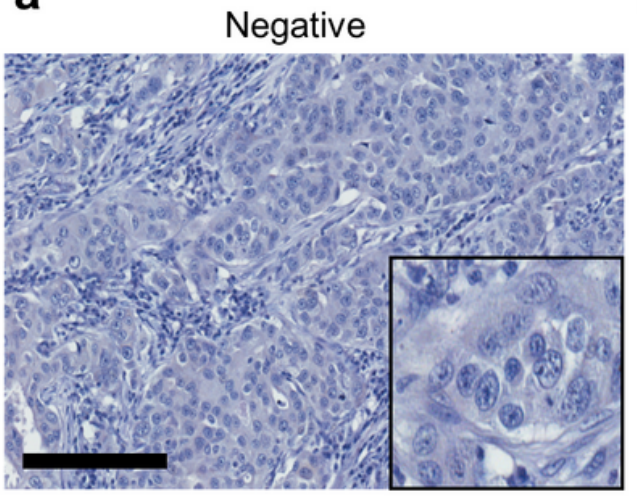

d

Normal mammary gland

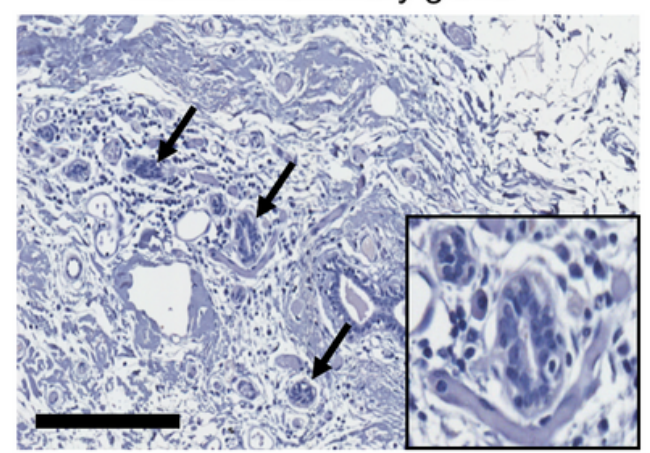

g

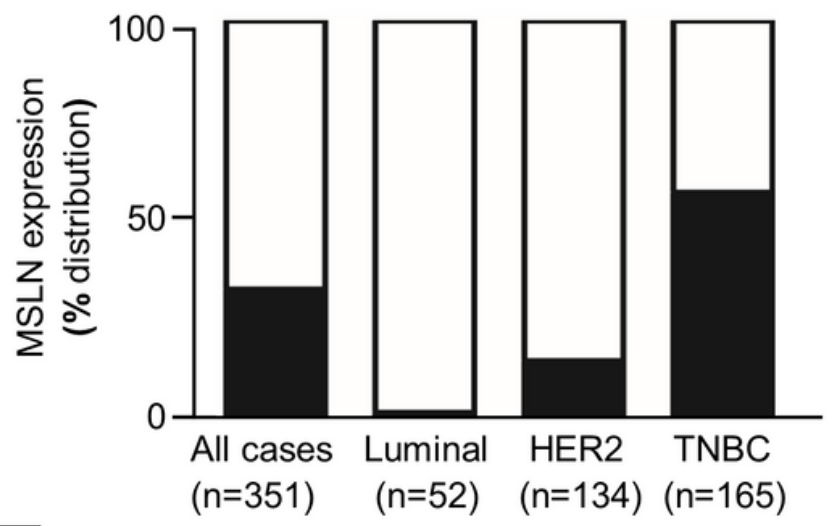

$\square$ Negative 236

Positive 115 b

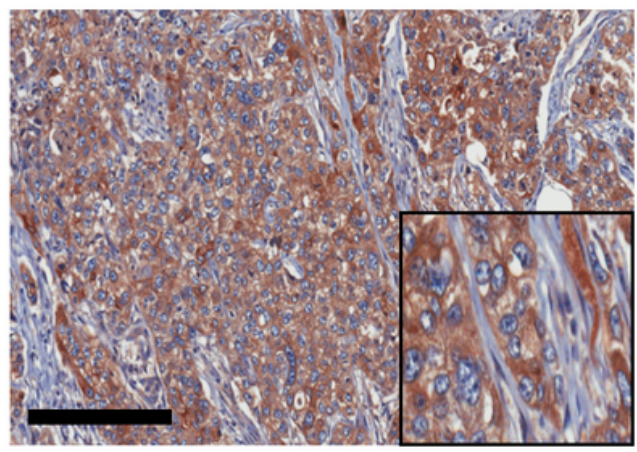

e
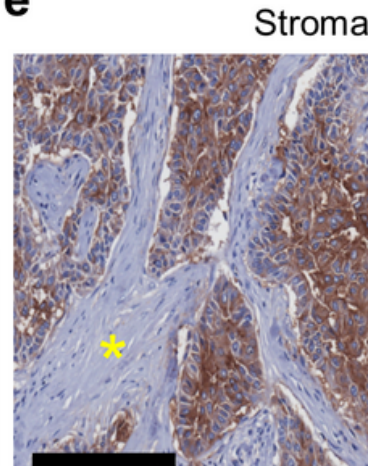

C

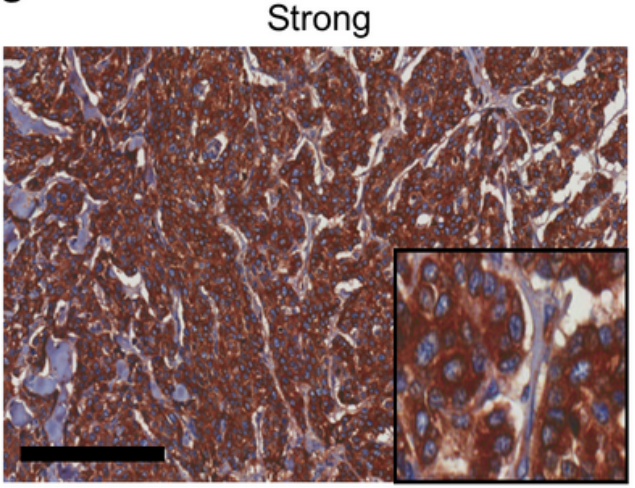

f
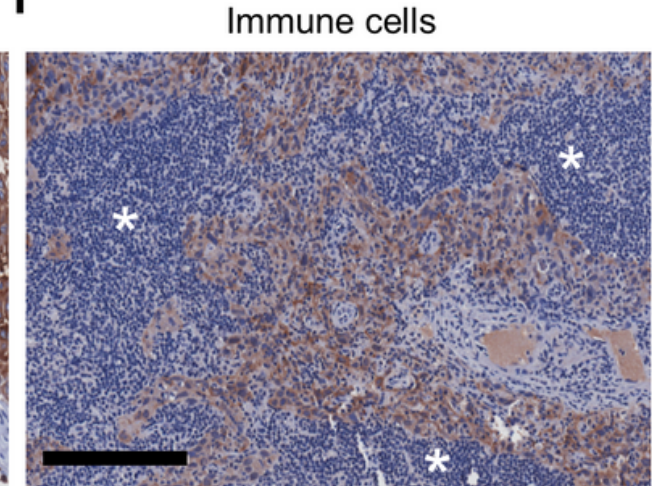

h

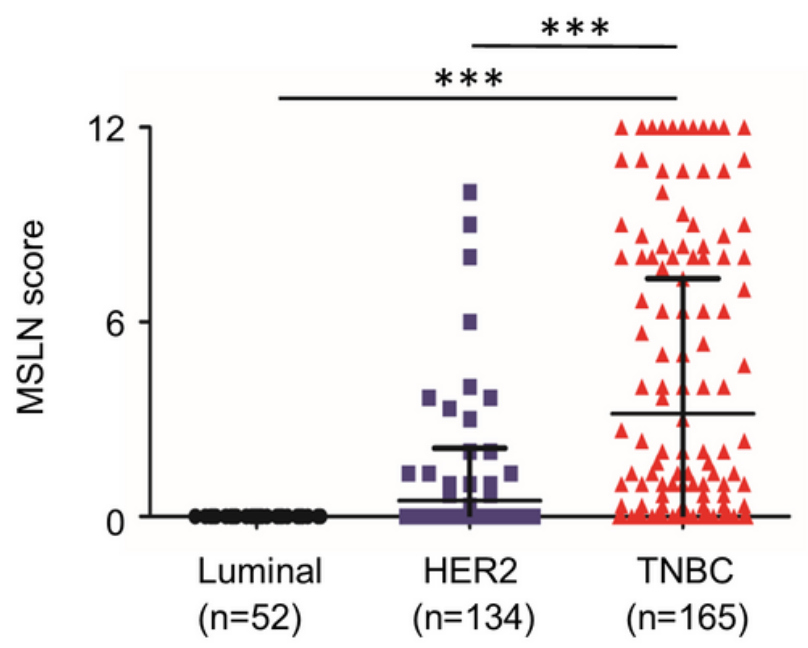

\section{Figure 1}

Expression of MSLN in human breast cancer tissue samples. a-c Representative of MSLN expression levels in breast cancer tissues ranging from negative (a), moderate (b) and strong staining (c). d Normal lobules (black arrow) showed no MSLN expression. The negative staining of MSLN in stromal cells (yellow asterisk) (e) and immune cells (white asterisk) (f). g The proportion of MSLN expressing samples in full cohort and stratified subtypes. $\mathrm{h}$ The mean MSLN score stratified by subtypes of breast cancer. Original magnification of $200 x$ and scale bars equal $200 \mu \mathrm{m} .{ }^{* \star *} \mathrm{p}<0.001$. 
a

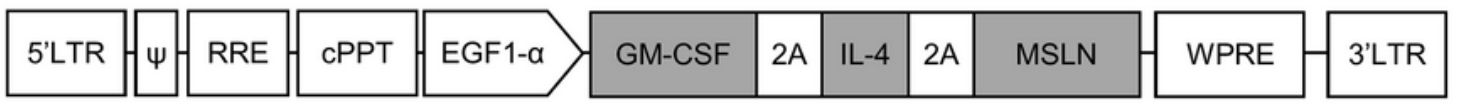

b

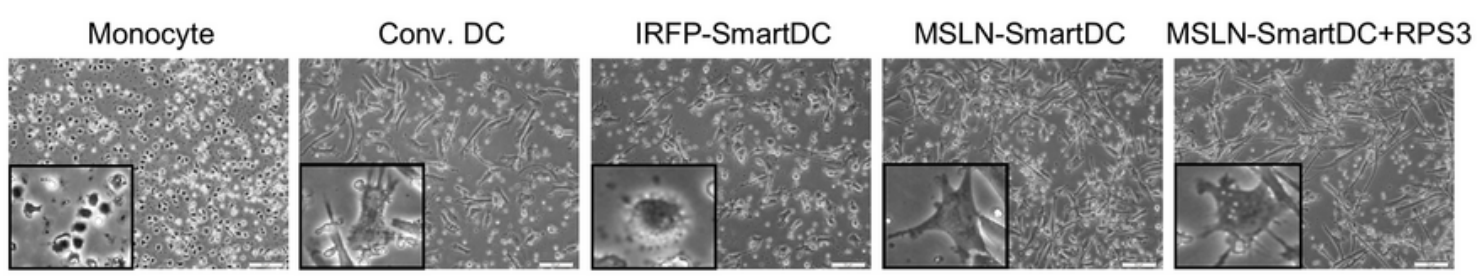

C

GM-CSF

d
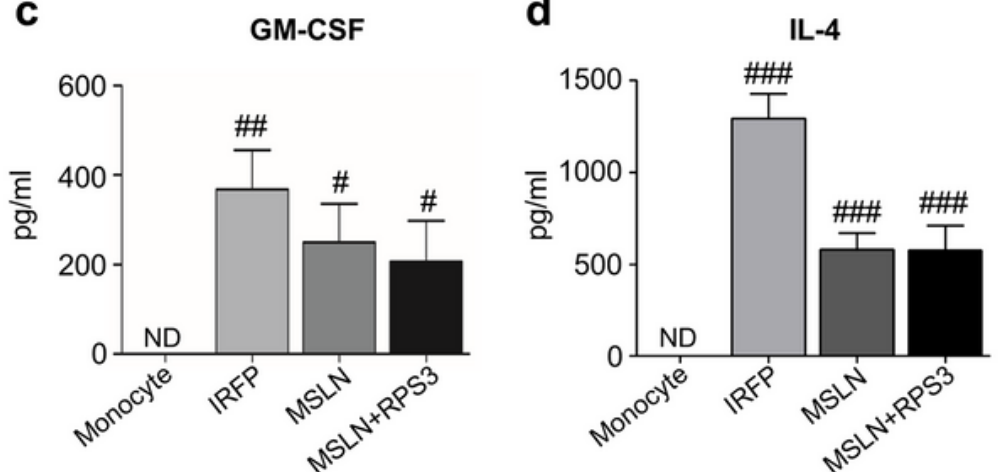

e

CD14

f
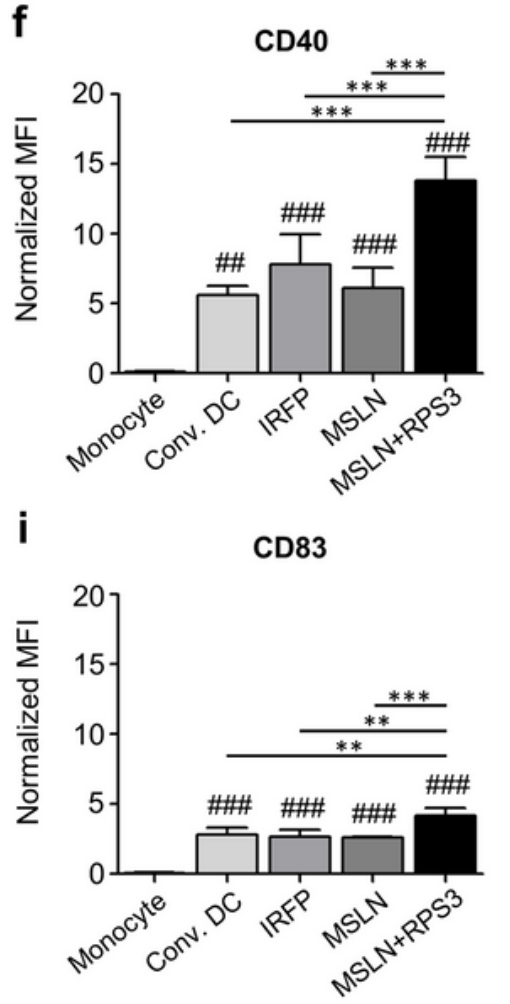

g
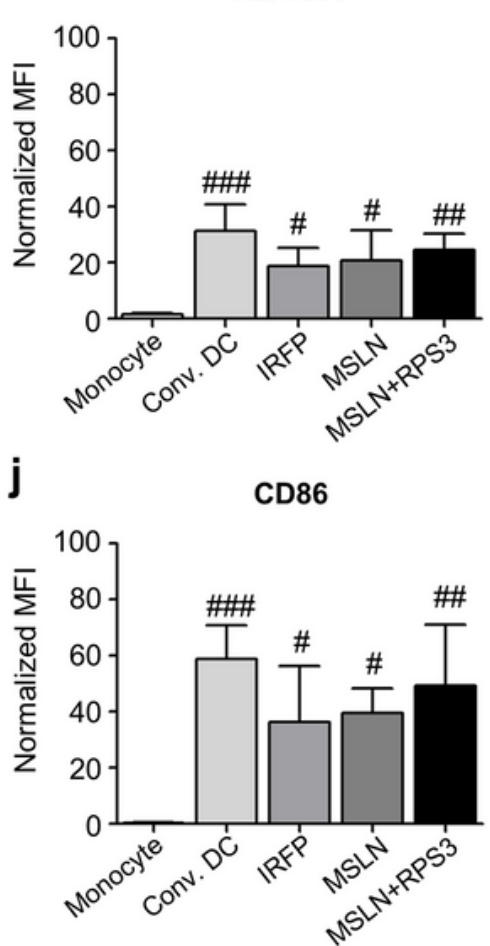

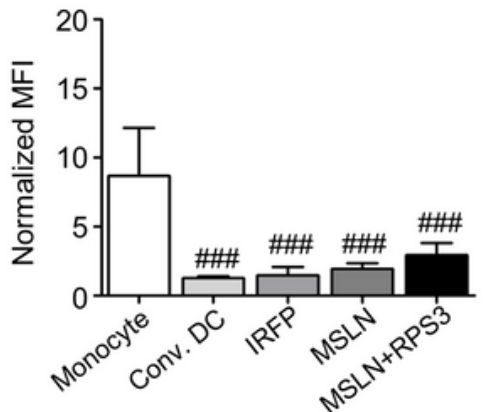

h
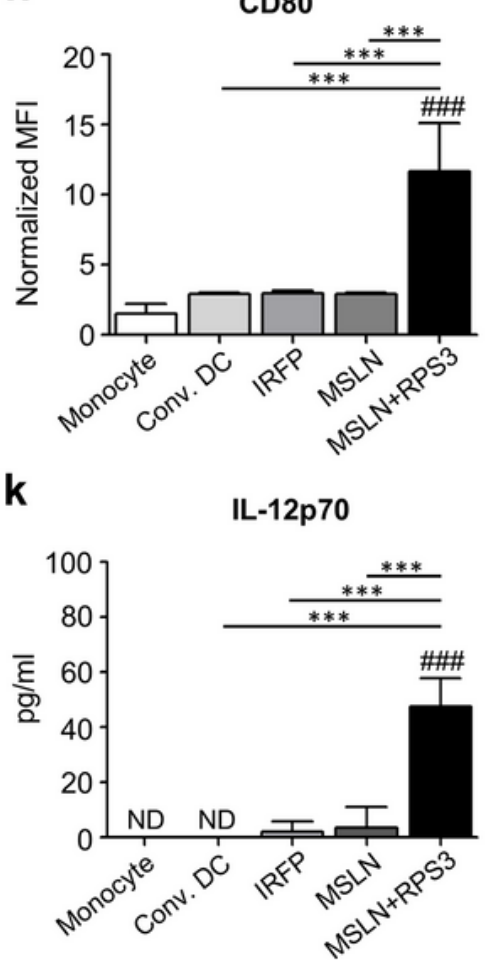

Figure 2

The lentiviral vector schematic maps and immunophenotype of MSLN-SmartDC and RPS3-MSLNSmartDC. a The construct of MSLN-SmartDC lentiviral vector. $b$ The representative pictures of monocytes at day 0 and DCs at day 7 of the experiemnt. Production of GM-CSF (c) and IL-4 (d) by monocytes and different DCs. e-j Expressions of surface markers of DCs in different treatment conditions including CD14 (e), CD40 (f), HLA-DR (g), CD80 (h), CD83 (i) and CD86 (j) in monocytes and DCs. Production of IL-12p70 
(k) by monocytes and different DCs. Magnification of 100x and scale bar equals $50 \mu \mathrm{m}$. The results were collected from 4 independent experiments. ${ }^{\#} p<0.05,{ }^{\# \#} p<0.0$ and ${ }^{\# \# \#} p<0.001$ compared to monocytes. ${ }^{*} p<0.01$ and ${ }^{* \star *} p<0.001$.

a

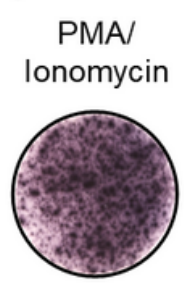

1037
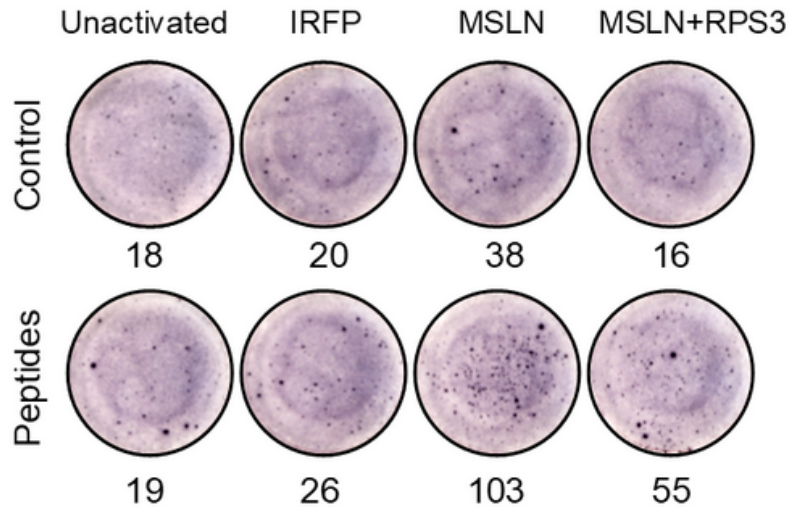

b
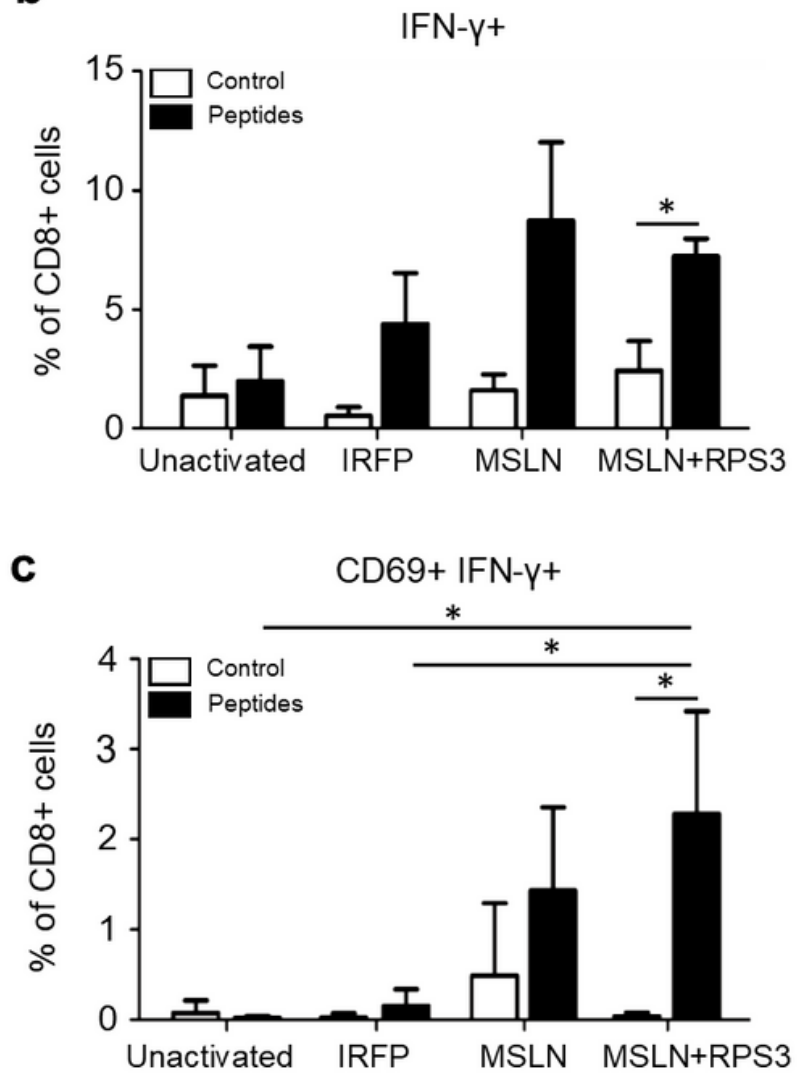

Figure 3

a Representative ELISpot well images and the quantification of IFN-y secreting cells after restimulation with MSLN antigenic peptides. $b$ and $c$ The frequency of IFN- $\gamma^{+}(b)$ and MSLN-specific T cells (CD69+ IFN$\left.\mathrm{Y}^{+}\right)(\mathrm{c})$ gated from $\mathrm{CD} 8^{+} \mathrm{T}$ cells after restimulation with MSLN antigenic peptides. The results were collected from 3 independent experiments. ${ }^{*} p<0.05$. 
a
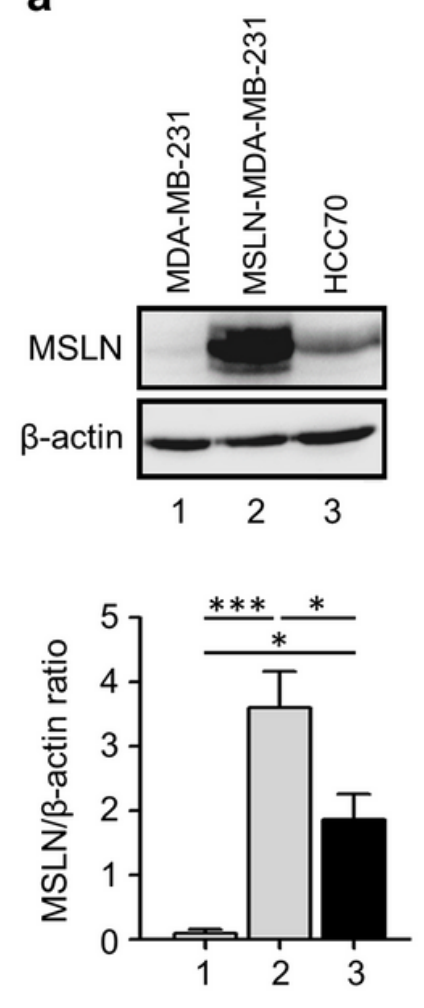

b

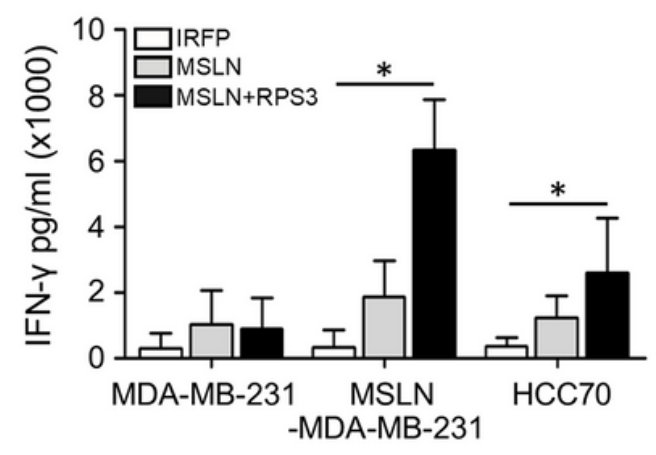

d

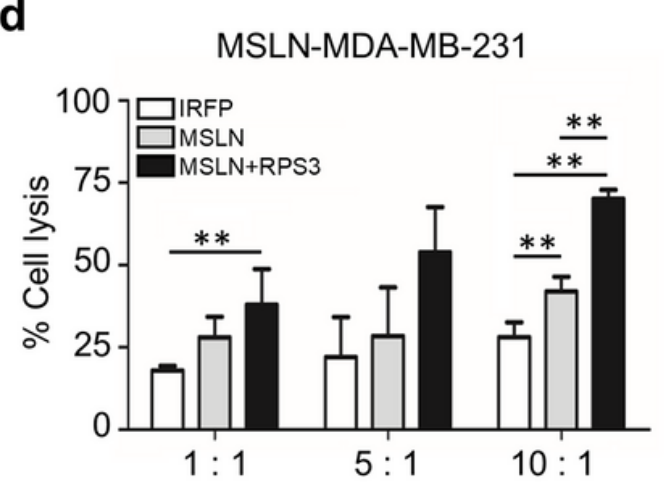

C

MDA-MB-231

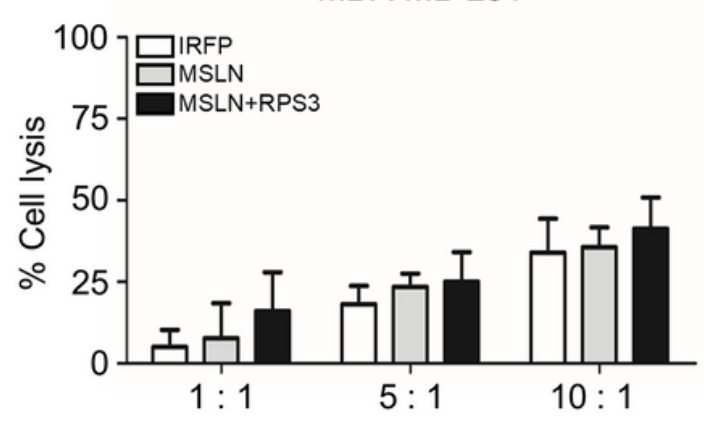

e

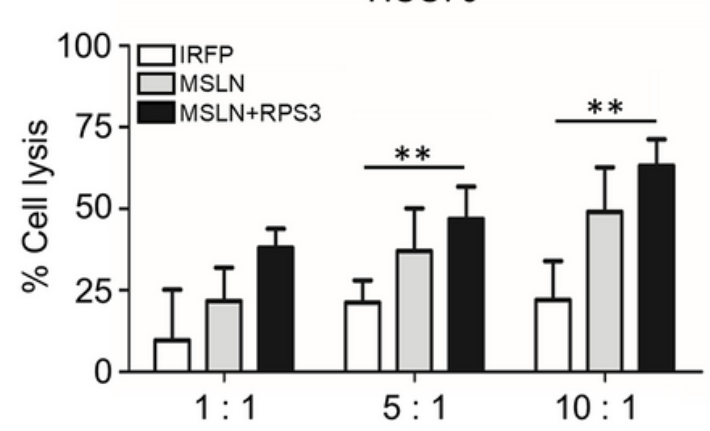

Figure 4

MSLN expression in TNBC cells and 2-D killing assay by T cells activated by MSLN-SmartDC and RPS3MSLN-SmartDC. a Western blot analysis of MSLN in TNBC cell lines. b IFN- $\gamma$ concentration in culture medium after $24 \mathrm{~h}$ of co-culturing with MDA-MB-231, MSLN-MDA-MB-231 and HCC70 at Effector cell:Target cell (E:T) ratio at 10:1. c-e Percentage of cell lysis of MDA-MB-231 (c), MSLN-overexpressing MDA-MB-231 (MSLN-MDA-MB-231) (d) and HCC70 (e) co-cultured with activated T cells at various ratios of $E$ :T. The results were collected from 4 independent experiments. ${ }^{*} p<0.05,{ }^{*} p<0.01$ and ${ }^{* \star *} p<0.001$. 
a
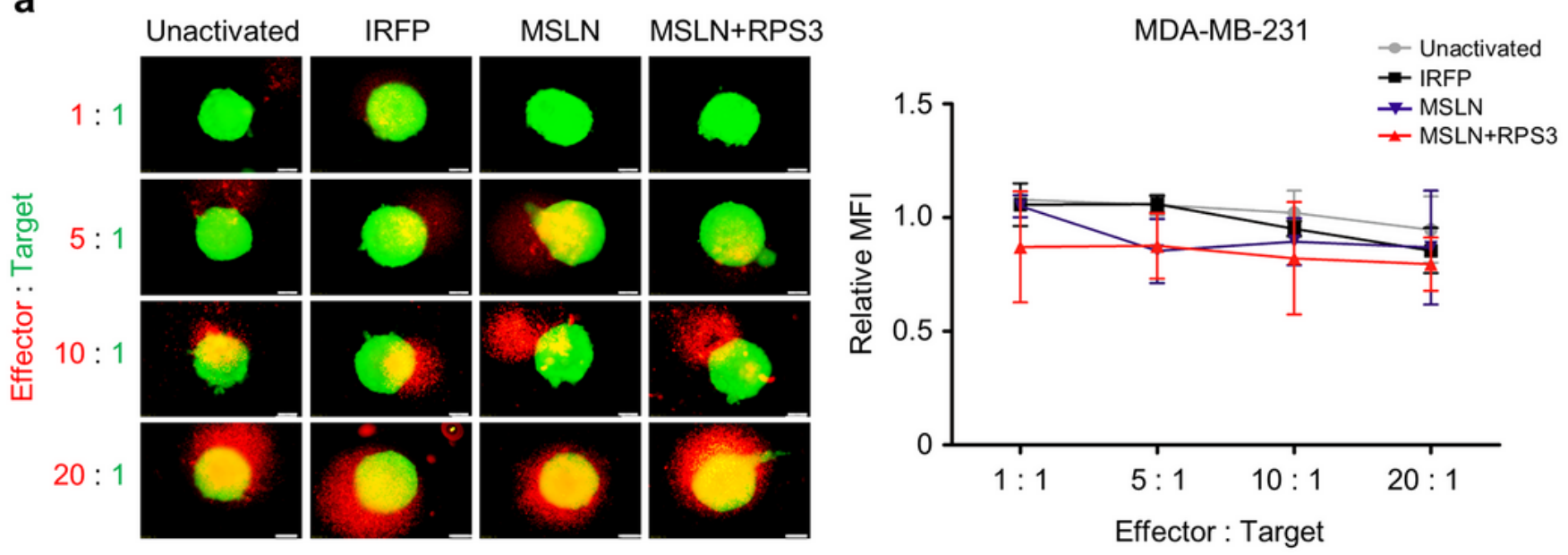

b
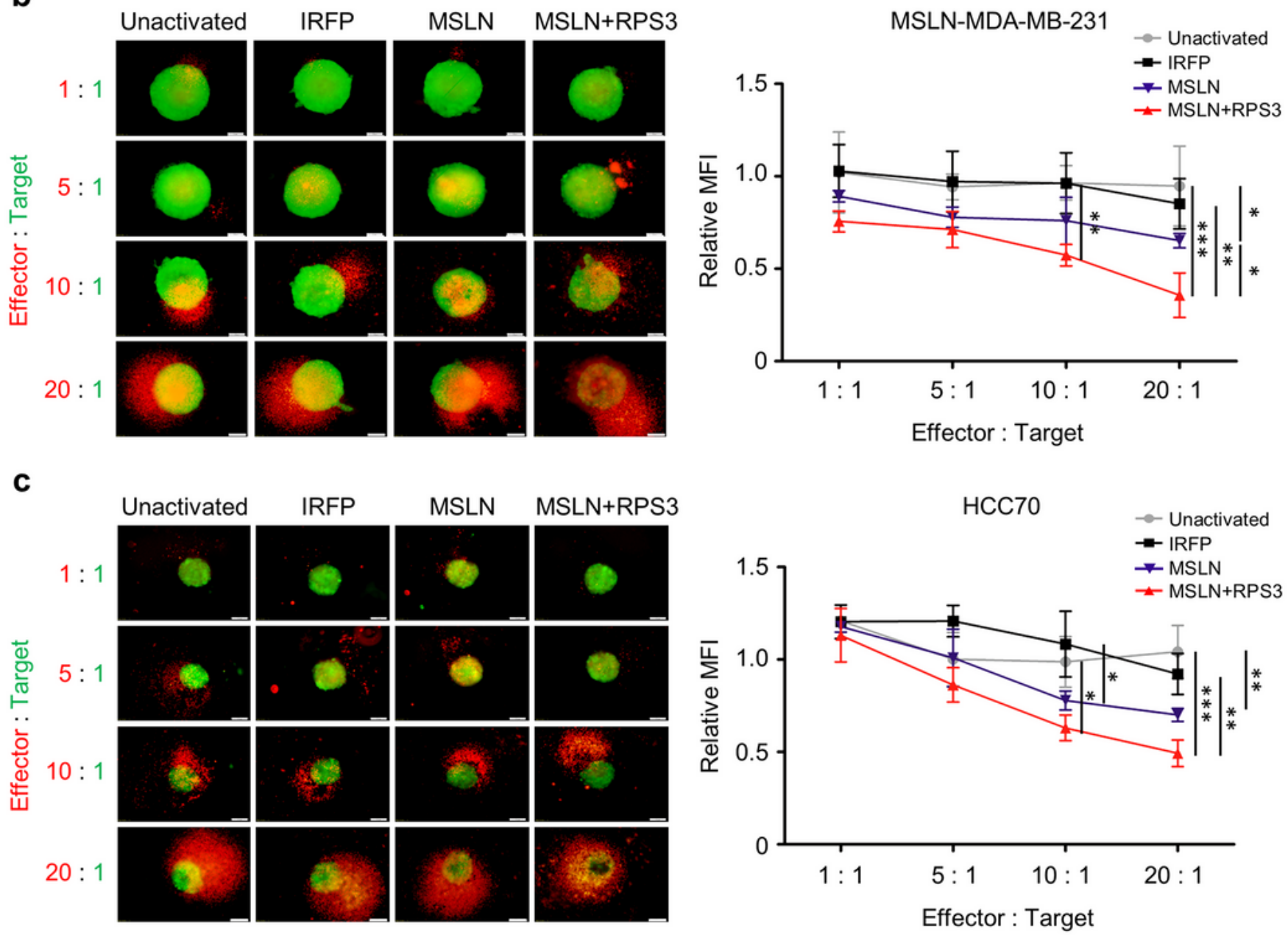

\section{Figure 5}

Cytotoxicity of cancer cells mediated by MSLN-SmartDC- and RPS3-MSLN-activated T cells in 3-D cancer spheroid assay. a-c Representative cancer spheroid (green) co-cultured with T cells (orange) for $48 \mathrm{~h}$ and the changes in mean fluorescence intensity (MFI) of mWasabi signal in MDA-MB-231 (a), MSLN-MDAMB-231 (b) and HCC70 (c) representing the remaining viable cancer cells after exposure to T cells. The results were collected from 4 independent experiments. ${ }^{*} p<0.05,{ }^{*} p<0.01$ and ${ }^{* * *} p<0.001$. 


\section{Supplementary Files}

This is a list of supplementary files associated with this preprint. Click to download.

- S1.png

- S2.png 